\title{
6 Sustainable development as the ultimate target of adopting a nexus approach to resources management
}

\author{
Serena Caucci, Lulu Zhang, Karla Locher-Krause, \\ and Stephan Hülsmann
}

\section{Introduction and aim}

Resource productivity and sustainable development: Challenges and limitations

The United Nations' Agenda for Sustainable Development underlines 17 Sustainable Development Goals (SDGs) with 169 targets. The lack of holistic knowledge on the interdependency between the SDGs and an interpretation of cause-and-effect relationships that connect the SDGs enormously challenges national policymakers that must implement that are in charge of implementing the 2030 agenda at the national level and achieving the goals across environmental, economic, and social dimensions (Griggs et al. 2017; Dörgo et al. 2018). The international scientific community started to measure the trade-offs and synergies between SDGs. For this exercise, it proved helpful to make use of the concept of the water-energy-food (WEF) nexus, which showed that when addressing challenges like water, energy and food security, integrated approaches to resources management across these sectors should be used and dependent resources considered equally (Hoff 2011). The WEF nexus concept is now starting to be implemented and is recognised as an essential tool for achieving and monitoring progress towards SDGs (Bleischwitz et al. 2018; Hülsmann \& Ardakanian 2018).

Nevertheless, the WEF is still challenged by a few limitations, in particular concerning comprehensive coverage of the interlinkages between sectors and resources (Albrecht et al. 2018). Besides, nexus assessments are only starting to address all dimensions of sustainability, including the environmental aspect, one primary reason being that ecosystem services (WEF-E) are hardly reflected in nexus tools (Hülsmann et al. 2019). This chapter aims to highlight the necessity of including innovative tools in the assessment of the WEF nexus approach to adopt resources management to achieve Sustainable development. To effectively counteract the potential trade-offs across SDGs, holistic ecosystem management and sustainable practices are required to increase resource productivity.

Sector-oriented resource management often neglects the potential impacts (trade-offs and synergies) on other resources or sectors, causing less resource 
use efficiency and productivity, thus, increasing the risk of unsustainability (Zhang \& Schwärzel 2017a). Exemplification result of this management is the food production sector and its supply that became the lead consumer of nearly $30 \%$ of the total global energy and 70\% of freshwater resources (FAO 2011). A shift from single-sector/resource-focused management to nexus-oriented resource management is thus a more effective way to deal with the complexity of interactions across sectors, resources, and SDGs under a changing global context (Zhang \& Schwärzel 2017b; Nilsson et al. 2018).

Food (SDG2) and water (SDG6) are closely interlinked and to achieving higher food production to guarantee food security for an ever-growing world population significantly depends on more water (in sufficient quality), and land or much higher productivity is required. For productions of quality food, fertile soils and clean water are necessary. However, boosting crop yields in food production implies an intensification of agricultural practices which typically goes along with land and water degradation. Contemporarily, the agriculture produce, biomass and agricultural wastes are potentially a source of renewable energy that creates competition between food (SDG2) and energy (SDG7) security over the same land and water resources. Moreover, using agricultural waste for energy instead of implementing composting and mulching may also decrease soil fertility in the long term.

Boosting the production of food and energy crops, even if primarily achieved by increased efficiency (thus without extending agricultural areas at the expense of natural forests and other terrestrial ecosystems) may compromise ecosystem services supply if not achieved sustainably. It may also compromise the social dimension of sustainability, for example, if working conditions and social standards in the agriculture sector are poor. The intrinsic trade-off briefly outlined for the WEF nexus clearly shows that resource productivity/efficiency only partially represents sustainability which should instead be understood in a broader sense.

\section{WEF-E: Mitigating trade-offs between resource productivity and sustainable resource management}

Demand for natural resources utilisation has reached dangerous limits threatening ecosystem functions together with the services that they provide to support essential human well-being (Foley et al. 2011). Evidence from natural system modifications shows that farmlands dominate $38 \%$ of the global surface and these sectors (energy and agriculture) are likely to remain dominant drivers of change (Zabel et al. 2019). This increased demand and competition for resources together with the current degradation of land and water systems make clear the need for action at different levels to mitigate natural resources depletion. Understanding how the ongoing land-use change and socioeconomic transitions can be turned from a challenge into an opportunity is critical to achieve sustainable development. As highlighted by the United Nations during the recent High-Level Policy Forum (HLPF 2018), such a 
challenge though needs to be tackled if Sustainable development goals (SDGs) have to be implemented. The reason of the disparities between the social demand and the total capacity of ecosystems to provide goods lies in (1) the so far adopted non-holistic natural resource management and in (2) missing measurable involvement of the society both in terms of participation and benefits (Seppelt et al. 2011; Mach et al. 2015; Hülsmann et al. 2019).

The ecosystem services approach addresses the interconnection between ecosystem services supply and societal demands, providing critical information to disentangle the interconnection between sections (nexus assessments). Furthermore, the approach seeks for a better understanding of the components and functions of socioecological systems, by separating the multiple services and benefits from ecosystems taking into consideration trade-offs and synergies within them (Carpenter \& Folke 2006; Rockström et al. 2009; Cord et al. 2017). The information contained in the trade-off and synergies put on the value the importance of ecosystem services for human well-being. Such information are obviously essential for integrated resources management and central element in nexus assessments (for example, De Strasser et al. 2016; Liu et al. 2017). The integration of ecosystem service would thus turn the WEF nexus into a WEF-E nexus (Carmona Moreno et al. 2018).

However, thus far, this has hardly been practised or implemented (Hülsmann et al. 2019). In this context, considerations of the spatial and temporal scale are crucial since ecosystem functions and processes are scaledependent (Grêt-Regamey et al. 2014; Raudsepp-Hearne \& Peterson 2016).

\section{The need to integrate ecosystem service modelling}

As mentioned above, on a conceptual level, it is well established that ecosystem services need to be included in nexus assessments. One primary reason why this has thus far not and if, only rudimentarily, established, is that ecosystem services are not adequately reflected in nexus tools. In general, considering several interconnected resources and sectors and the respective processes, fluxes, and actors involved requires making use of appropriate nexus tools for their assessments. Currently, a high and increasing number of tools is available and in use. Such tools include newly designed models addressing the WEF nexus (Kaddoura \& El Khatib 2017) as well as the water-energy nexus (Dai et al. 2018) or established tools and concepts which are reframed in nexus context (e.g. life cycle assessment tools). Model frameworks coupling multiple sector-oriented models for nexus assessments are also part of nexus tools.

Nevertheless, the ecosystem perspective was primarily ignored (Howells et al. 2013). Likewise, Albrecht et al. (2018) concluded from an in-depth analysis of current nexus models that all of them fail to consider critical interlinkages, ecosystem services being among the neglected aspects. This fact is of relevance because the supply of one or more ecosystem services could underpin the impact on several SDGs and sectors. 
However, some recent case studies and assessments do explicitly account for (specific) ecosystem services within nexus assessments (Martinez-Hernandez et al. 2017; Karabulut et al. 2018; Hanes et al. 2018) based on newly developed tools. At least conceptually, potential pathways on how to better integrate ecosystem services into nexus tools have been proposed (Hülsmann et al. 2019). The main argument for doing that is the need to cover all aspects of sustainability (social, economic and environmental) and address the interconnected SDGs in a comprehensive manner. As argued before (Hettiarachchi \& Ardakanian 2016; Hülsmann \& Ardakanian 2018; Liu et al. 2018), adopting a nexus approach will be instrumental in achieving SDGs. Any effort towards integrative approaches (e.g. WEF nexus) should be appreciated and will facilitate the unlocking of synergies and minimising trade-offs, thus increasing resource productivity. Ultimately, however, as long as environmental aspects are largely ignored, sustainability is not 'complete' and respective SDGs, e.g. SDG 13 (climate action), SDG 14 (life below water) and SDG 15 (life on land) not adequately addressed. Therefore, the WEF nexus should be extended to a WEFE nexus. With regard to nexus tools, this implies making use of a wide range of models, combine and couple them as required, considering the ecosystem perspective. The choice of the most appropriate (suite of) model(s) might be facilitated by respective model platforms providing detailed information about available tools (Mannschatz et al. 2016).

\section{The need to integrate participatory approaches}

Another sustainability dimension typically neglected in nexus assessments is the social one. Addressing it requires adopting a participatory approach (Caucci \& Hettiarachchi 2017; Benavides et al. 2019). Linking the complexity of participatory processes to their outcomes to the societal impact of resource management is thus fundamental when targeting Sustainable Development.

Implementation of WEF nexus and the ecosystem services approach can also be fostered by governance practices and participation which are used across different scales when resource management is applied. The participatory components toward Nexus oriented solutions base their effectiveness on the tight interaction between societal stakeholders and resource evidence-based decisions. If properly performed, the outcome of this approach is more socially robust management, actionable knowledge, or sustainable actions (Wiek et al. 2012; de Jong et al. 2016).

Unfortunately, while most nexus research-oriented studies call for theoretic stakeholder participation, empirical evidence on co-creation of action-oriented measures are often missing. The lack of action-oriented measures is aften due to little guidance on how to integrate this tool into the nexus assessment when stakeholders and their role has to be defined. Roidt and Avellán (2019) showed how limited resource management has been when stakeholders are not considered fully into the nexus assessment. The mere biophysical scale of resource management (tools) is insufficient to capture interests and social relations of actors that are not directly confined in the physical boundaries defined by the studies, and 
thus a multi-scalar approach should be used (Benavides et al. 2019). Moreover, natural resources management intrinsically own a high level of 'wickedness' that could slow down the deployment of policies addressing resource management in a Nexus perspective. Governance participatory approaches are thus a valuable instrument to target Sustainable Development (Kirschke et al. 2018). The explicit representation of this approach in nexus tools could reduce the risk of overlooking barriers impacting the definition of nexus oriented-solutions that instead aim at balancing resource productivity and natural resource management.

\section{Reconsidering the WEF nexus approach under other lenses}

Exemplification of concepts in case studies often helps in highlighting good practices and supports the identification of shortcomings (UNU-FLORES 2016; Hettiarachchi et al. 2019). As environmental resources such as water, soil, and waste become increasingly exposed to the impacts of climate change and socio-economic pressure, nexus assessment must go beyond outdated resource management approaches that ignore this interdependence. With the below examples, we intend thus to analyse the helpfulness of the nexus approach toward Sustainable Development. At the same time, criticism to the approach as well as a suggestion for its implementation via the integration of newer nexus tools will be provided.

\section{Case study 1}

This case study examines water reuse in agriculture and multipurpose sustainable wastewater management as an application of the nexus approach. The content is based on 'Safe Use of Wastewater in Agriculture: Good Practice Examples' (UNU-FLORES 2016).

Water reuse and wastewater management have a direct impact on the availability and quality of resources such as water and soil when reused in agriculture. Wastewater used in irrigation not only addresses the water demand in waterstressed areas but also helps us 'recycle' the nutrients in it. Sustainable solutions that consider interdependencies when water is managed and reused are exemplified in two projects namely SludgeTec (Resource recovery from wastewater in the Americas - Assessing the Water-Soil-Waste Nexus) and SUWA (Safe Use of Wastewater in Agriculture). The two projects employ a Nexus Approach that focus on understanding resource flows across different scales. The Nexus-assessment performed in the project includes a participatory approach for sustainable decisionoriented options aiming at buffering water scarcity and poor wastewater management. Using this methodology, 16 case studies in the Global South were analysed and results revealed the potential benefits and implications for other sectors and resources, and related SDGs such as health (SDG 3) and food production (SDG 2), thus maximising the co-benefits. Among the sixteen cases analysed, the challenges that the countries had to face at the interface of water, soil, and waste were not unique. The problem in most of the case studies was not the lack of knowledge and 
resource but rather poor data management, incoherent policy definition for sustainable resource management and the lack of holistic governance enforcement.

In detail, two of the case studies (Mexico and Guatemala) were analysed via multi-method research that combines the baseline description of the case, the definition of the desired target state (sustainable use and management of wastewater) and pathways towards their achievement while applying the nexus approach (UNU-FLORES 2016). The assessment had a transdisciplinary profile, and it has integrated sustainability assessment, social network analysis and wickedness analysis. The application of this approach yielded orientations for action much beyond technical implementation and definition of financial models (Hettiarachchi et al. 2018), and it instead, recommended actions toward a better information collection system and improved information sharing among actors for better decision making. The recommendations provided after the study allowed local stakeholders to take up the ownership of their solution paths and contributed to the resolution of technical issues. Innovative solutions to overcome the nonsustainable water uses have been raised by the participatory process and a citizen observatory for the community-based monitoring system was voted as the best solution in Guatemala, while an open neighbourhood discussion forum and digital media campaign were established by the stakeholders in Mexico.

These two cases clearly show the benefits of an integrated approach both in terms of increased resource efficiency and acceptance of changes. However, the impact of wastewater irrigation practices on the groundwater ecosystem or the impact of wastewater management on public health has been not fully considered. This mainly related to the siloed thinking approach used to identify trade-off and synergies or by the lack of integration of participatory approaches when management practices of resources were enforced. In the future, changes toward a more holistic decision making and management strategies for implementation measures should take place considering the ecosystem services involved in such changes. The SUWA initiative and SludgeTec projects, despite the limitation on ecosystem service inclusion, do provide recommendations on the sustainably accepted solution in terms of management. The projects are also highlighting the need of newer cooperation among ministerial sectors that would include more holistic management of resources thus capitalising on the synergies that these resources could provide to the society in the long run (Caucci \& Hettiarachchi 2017). SludgeTec project also indicates co-participatory accepted solutions as a node for a sustainable development and resulting from a multidisciplinary framework assessment. These solutions range between technical accepted solution, social inclusion and data availability improvement that should be addressed via publicly available databases and platforms.

\section{Case study II}

This case study examines integrated reservoir management in the Durance-Verdon basin, France, as an application of a WEF nexus approach. The content is based on Hülsmann, Rinke, Paul and Diez Santos (in press). 
Reservoirs increasingly serve multiple uses and provide diverse types of ecosystem services: water is needed for irrigation for crop production, for domestic and industrial use, aquaculture, energy production and storage, ecosystem services, recreation and navigation. Also, storage capacity is required for flood control and drought management. All of these concurring and partly competing water uses need to be considered to maximise co-benefits, minimise trade-offs and deliver services in a synergetic way. This balancing needs to take the temporal variability of water demands as well as site-specific priorities into account. Reservoir management, therefore, requires adopting a nexus approach. Considering the multiple uses of multipurpose hydropower reservoirs in a comprehensive way was the aim of an initiative by Électricité de France (EDF) and the World Water Council (WWC). The SHARE concept (Branche 2017) was proposed as a framework to address the issue of competing for water uses in reservoirs where hydropower is one of them. In this context, SHARE stands for Sustainability approach for all users, Higher efficiency and equity among all sectors, Adaptability for all solutions, River basin perspective for all and Engaging all stakeholders, issues which are all considered essential for a nexus approach.

Among the twelve case studies analysed, the Durance-Verdon basin in France was one of the few indeed multifunctional cases covering virtually all possible uses, demonstrating clear co-benefits and synergies. Drinking water provision, irrigation and tourism were important uses creating benefits, including jobs in the region. Via integrated management water demand by irrigation was decreased by $30 \%$, indicating that governance structures and implemented management schemes, including tariff systems and economic incentives, effectively supported resource use efficiency. Overall, it was shown that the non-power benefits were considerably higher than hydropower benefits alone.

The case of a multipurpose reservoir in the Durance-Verdon basin clearly shows the benefits of integrated management in terms of increased resource efficiency. A neglected aspect was, however, the impacts on ecosystems, mainly related to the disruptive effects of dams. The impact on the ecosystem is a major argument against dams in general, and thus the risk of damaging the ecosystem must be addressed during the planning phase. Once established, the barrier effect can only partly be compensated. However, other adverse effects, e.g. alterations in the thermal regime of the river system can be minimised by managing the discharge from several depth horizons if variable outlets are available (Weber et al. 2017). The SHARE initiative, despite showing casespecific decision on how to allocate water between the different uses and users, provides valuable indications on suitable institutional arrangements to improve the sustainability of water resource management, e.g. basin committees. The case studies also indicate suitable management tools, ranging from planning documents and guidelines to tariff systems and data sharing policies and platforms.

The case studies outlined above, albeit targeting quite different systems, clearly demonstrate the benefits of integrated resources management in terms of increased 
resource use efficiency. They also provide evidence on the importance of stakeholder involvement and a governance dimension of the nexus (Hettiarachchi et al. 2018). Similar to the conclusion drawn by Hülsmann et al. (2019), the ecosystem perspective was, however, neglected in both cases. Concerning wastewater irrigation, environmental impacts, e.g. on groundwater quality (Caucci \& Hettiarachchi 2018; Jampani et al. 2018) or health (Caucci \& Meyer 2017) were thus far not fully considered. In the case of reservoir management, notwithstanding various benefits for several sectors, the environmental impacts were not considered in the assessment offered by Branche (2017).

Overall, the cases demonstrate that a cross-sectoral or Nexus Approach, such as WEF or the Water-Soil-Waste (WSW), enhances the synergies towards achieving the SDGs by improving the use-efficiency of natural resources, closing carbon and nutrient cycles and recycling waste as well as balancing the supply and demand of ecosystem services (Lal 2015). However, the success of the implementation largely depends on the coordination across sectors and society, in which a unified understanding of the interdependence of SDGs and shared benefits among users, stakeholders, and politicians must be reached (Zhang \& Schwärzel 2017b; Benavides et al. 2019).

To this end, we need to focus on integrative approaches of different interlinking sectors which offer sustainable solutions and adaptive strategies to ensure food, energy and water supply for the future, which was the fundamental motivation behind the nexus concept (Hoff 2011). Here, we argue that too often the focus of nexus assessments was on increasing resource use efficiency, neglecting the environmental and social dimensions and the inherent trade-offs. Sustainable Development indeed calls for a nexus approach to resources management that, while certainly aiming at increased productivity, considers all dimensions of sustainability at the level considered suitable (local, regional, and global) for the nexus case.

\section{Conclusions}

\section{The need to consider the social and environmental dimensions in the implementation of the nexus approach for sustainable development}

A vital component of achieving solutions is to define the roots of the problems and deal with them instead of mitigating their consequences (Husemann et al. 2013). For this, improved monitoring, modelling, and projecting technologies are essential to facilitate a common understanding of the problem and provide decision-makers and stakeholders with more precise and accurate information regarding trade-offs on ecosystem services (Zhang \& Schwärzel 2017b; Benavides et al. 2019). The aspect of achieving a common understanding is indeed essential to ensure the success of the implementation of management initiatives. Identifying the appropriate mix of stakeholders is one crucial step which can be aided by social network analysis (Kurian et al. 2018; Avellán et al. 2019). 
Co-creation and sharing of knowledge can be achieved using various tools to ensure stakeholders participation, to first to define the nexus problem and later to identify potential sustainable solutions. The first step can, for example, be supported by workshops, round tables and serious thematic games (Johnson \& Karlberg 2017; Mochizuki et al. 2018; Benavides et al. 2019), the second step may involve participatory modelling (Smajgl 2018). Tools for both steps should ideally consider all dimensions of sustainability. The use of tools and co-participatory approaches gives confidence that nexus approaches would be a better way for developing adaptive solutions and measures for resource management, ultimately, ensuring sustainable development.

\section{Recommendations}

This chapter aims to highlight the necessity of including innovative tools in the assessment of the WEF nexus approach to adopt resources management to achieve Sustainable development. To effectively counteract the potential tradeoffs across SDGs, holistic ecosystem management and sustainable practices are required to increase resource productivity. However, the ecosystem perspective, essential for sustainable resources management, has been identified as a missing element within earlier nexus assessments. Integrating the environmental (i.e. ecosystem services) and social dimensions (i.e. participatory approaches) are crucial in WEF assessments and an improvement of Nexus tools implemented. This would guarantee both the impact of resource management in the society and the social and political dimensions of water, energy, and food. Participatory methods to engage researchers, practitioners, local decision-makers, and communities provide knowledge-sharing activities that contribute to the coproduction of solutions. Participatory methods are also able to measure sociopolitical context for resources efficiency management and ultimately when ecosystem services will be fully considered sustainable development.

\section{Abbreviations}

$\begin{array}{ll}\text { EDF } & \text { Électricité de France Fluxes and of Resources } \\ \text { SDGs } & \begin{array}{l}\text { Sustainable Development Goals } \\ \text { UNU-FLORES }\end{array} \\ & \begin{array}{l}\text { United Nations University Institute for Integrated } \\ \text { Management of Material } \\ \text { Water-energy-food }\end{array} \\ \text { WEF } & \text { water-energy-food-ecosystem } \\ \text { WWE-E } & \text { World Water Council }\end{array}$

\section{References}

Albrecht, T. R., Crootof, A., Scott, C. A. (2018). The Water-Energy-Food Nexus: A Systematic Review of Methods for Nexus Assessment. Environ Res Lett 13, 43002. doi: 10.1088/1748-9326/aaa9c6. 
Avellán, T. A., Hahn, A., Kirschke, S., Müller, A., Benavides, L., Caucci, S. (2019). Towards Sustainable Wastewater Systems - Applying a Triangular Research Method in a Nexus View in Two Cases in Latin America. Sustainability.

Benavides, L., Avellán, T., Caucci, S., et al. (2019). Assessing Sustainability of Wastewater Management Systems in a Multi-Scalar, Transdisciplinary Manner in Latin America. Water 11.

Bleischwitz, R., Spataru, C., VanDeveer, S. D., et al. (2018). Resource Nexus Perspectives towards the United Nations Sustainable Development Goals. Nat Sustain 1, 737-743. doi: 10.1038/s41893-018-0173-2.

Branche, E. (2017). The Multipurpose Water Uses of Hydropower Reservoir: The SHARE Concept. Comptes Rendus Phys 18, 469-478. doi: 10.1016/J.CRHY.2017.06.001.

Carmona Moreno, C., Dondeynaz, C., Biedler, M., et al. (2018). Position Paper on Water, Energy, Food and Ecosystem (WEFE) Nexus and Sustainable Development Goals (SDGs).

Carpenter, S. R., Folke, C. (2006). Ecology for Transformation. Trends Ecol Evol 21, 309-315. doi: 10.1016/J.TREE.2006.02.007.

Caucci, S., Berendonk, T. U. (2014). Environmental and Public Health Implication of Antibiotic Resistance Genes in Municipal Wastewaters. Prävention und Gesundheitsförderung 9, 175-179.

Caucci, S., Hettiarachchi, H. (2018). The Nexus Approach and Safe Use of Wastewater in Agriculture: A Workshop on Policy and Implementation for Tunisia. United Nations University Institute for Integrated Management of Material Fluxes and of Resources (UNUFLORES), Dresden.

Caucci, S., Hettiarachchi, H. ed. (2017). Wastewater Irrigation in the Mezquital Valley, Mexico: Solving a Century-Old Problem with the Nexus Approach 2017/03/15-17 Mezquital Valley. United Nations University Institute for Integrated Management of Material Fluxes and of Resources (UNU-FLORES), Dresden.

Caucci, S., Meyer, K. (2017). Your Future Food Will be Grown with Waste Water. The Conversation.

Cord, A. F., Bartkowski, B., Beckmann, M., et al. (2017). Towards Systematic Analyses of Ecosystem Service Trade-offs and Synergies: Main Concepts, Methods and the Road Ahead. Ecosyst Serv 28, 264-272. doi: 10.1016/J.ECOSER.2017.07.012.

Dai, J., Wu, S., Han, G., et al. (2018). Water-Energy Nexus: A Review of Methods and Tools for Macro-assessment. Appl Energy 210, 393-408. doi: 10.1016/J.APENERGY. 2017.08.243.

de Jong, M., Yu, C., Joss, S., et al. (2016). Eco City Development in China: Addressing the Policy Implementation Challenge. J Clean Prod 134, 31-41. doi: 10.1016/j.jclepro.2016. 03.083 .

De Strasser, L., Lipponen, A., Howells, M., et al. (2016). A Methodology to Assess the Water Energy Food Ecosystems Nexus in Transboundary River Basins. Water 8, doi: 10. 3390/w8020059.

Dörgo, G., Sebestyén, V., Abonyi, J. (2018). Evaluating the Interconnectedness of the Sustainable Development Goals Based on the Causality Analysis of Sustainability Indicators. Sustain 10, doi: 10.3390/su10103766.

FAO (2011). Energy-Smart Food for People Climate. 66.

Foley, J. A., Ramankutty, N., Brauman, K. A., et al. (2011). Solutions for a Cultivated Planet. Nature 478, 337-342. doi: 10.1038/nature10452.

Grêt-Regamey, A., Rabe, S.-E., Crespo, R., et al. (2014). On the Importance of Nonlinear Relationships between Landscape Patterns and the Sustainable Provision of Ecosystem Services. Landsc Ecol 29, 201-212. doi: 10.1007/s10980-013-9957-y. 
Griggs, D., Nilsson, M., Stevance, A., McCollum, D. (2017). A Guide To SDG Interactions: From Science to Implementation. Paris.

Hanes, R. J., Gopalakrishnan, V., Bakshi, B. R. (2018). Including Nature in the FoodEnergy-Water Nexus Can Improve Sustainability across Multiple Ecosystem Services. Resour Conserv Recycl 137, 214-228. doi: 10.1016/J.RESCONREC.2018.06.003.

Hettiarachchi, H., Ardakanian, R. (2016). Managing Water, Soil, and Waste in the Context of Global Change. In: Hettiarachchi, H., Ardakanian, R. (eds) Environmental Resource Management and the Nexus Approach: Managing Water, Soil, and Waste in the Context of Global Change. Springer International Publishing, Cham, pp 1-7.

Hettiarachchi, H., Caucci, S., Ardakanian, R. (2018). Safe Use of Wastewater in Agriculture: The Golden Example of Nexus Approach. In: Hettiarachchi, H., Ardakanian, R. (eds) Safe Use of Wastewater in Agriculture: From Concept to Implementation. Springer International Publishing, Cham, pp 1-11.

Hettiarachchi, H., Caucci, S., Schwärzel, K. eds (2019). Organic Waste Composting through Nexus Thinking. Practices, Policies, and Trends. Springer International Publishing (in press).

HLPF (2018). Report of the High-Level Political Forum on Sustainable Development Convened under the Auspices of the Economic and Social Council at its 2018 Session. E/HLPF/2018/7.

Hoff, H. (2011). Understanding the Nexus. In: Understanding the Nexus. Background Paper for the Bonn2011 Conference: The Water, Energy and Food Security Nexus. Stockholm Environment Institute, Stockholm.

Howells, M., Hermann, S., Welsch, M., et al. (2013). Integrated Analysis of Climate Change, Land-Use, Energy and Water Strategies. Nat Clim Chang 3, 621.

Hülsmann, S., Ardakanian, R. (2018). The Nexus Approach as Tool for Achieving SDGs: Trends and Needs. In: Hülsmann, S., Ardakanian, R. (eds) Managing Water, Soil and Waste Resources to Achieve Sustainable Development Goals: Monitoring and Implementation of Integrated Resources Management. Springer International Publishing, Cham, pp 1-9.

Hülsmann, S., Rinke, K., Paul, L., Diez Santos, C. In press. 'Storage Reservoir Management and Operation Including Complex Multiunit and Multipurpose Systems'. In Springer Handbook of Water Management, Bogardi, Janos (ed). Springer Berlin Heidelberg.

Hülsmann, S., Sušnik, J., Rinke, K., et al. (2019). Integrated Modelling and Management of Water Resources: The Ecosystem Perspective on the Nexus Approach. Curr Opin Environ Sustain 40, 14-20. doi: 10.1016/J.COSUST.2019.07.003.

Husemann, J., Espinosa-Gutiérrez, G., Tadesse, Y. B., et al. (2013). Towards Nexus Approach: Case Studies on Integrated Management of Water, Soil and Waste from China, Ethiopia, Iraq, Mexico, Serbia and South Asia. In: Hülsmann, S., Ito, M., Ardakanian, R. (eds) Proceedings of International Kick-off Workshop 'Advancing a Nexus Approach to the Sustainable Management of Water, Soil and Waste.' United Nations University Institute for Integrated Management of Material Fluxes and of Resources (UNU-FLORES), Dresden, pp 120-142.

Jampani, M., Huelsmann, S., Liedl, R., et al. (2018). Spatio-temporal Distribution and Chemical Characterization of Groundwater Quality of a Wastewater Irrigated System: A Case Study. Sci Total Environ 636, 1089-1098. doi: 10.1016/J.SCITOTENV.2018. 04.347.

Johnson, O. W., Karlberg, L. (2017). Co-exploring the Water-Energy-Food Nexus: Facilitating Dialogue through Participatory Scenario Building. Front Environ Sci 5, 24. doi: 10.3389/fenvs.2017.00024. 
Kaddoura, S., El Khatib, S. (2017). Review of Water-Energy-Food Nexus Tools to Improve the Nexus Modelling Approach for Integrated Policy Making. Environ Sci Policy 77, 114-121. doi: 10.1016/j.envsci.2017.07.

Karabulut, A. A., Crenna, E., Sala, S., Udias, A. (2018). A Proposal for Integration of the Ecosystem-Water-Food-Land-Energy (EWFLE) Nexus Concept into Life Cycle Assessment: A Synthesis Matrix System for Food Security. J Clean Prod 172, 3874-3889. doi: 10.1016/J.JCLEPRO.2017.05.092.

Kirschke, S., Zhang, L., Meyer, K. (2018). Decoding the Wickedness of Resource Nexus Problems-Examples from Water-Soil Nexus Problems in China. Resour. 7.

Kurian, M., Portney, K. E., Rappold, G., et al. (2018). Governance of Water-energy-Food Nexus: A Social Network Analysis Approach to Understanding Agency Behaviour. In: Hülsmann, S., Ardakanian, R. (eds) Managing Water, Soil and Waste Resources to Achieve Sustainable Development Goals: Monitoring and Implementation of Integrated Resources Management. Springer International Publishing, Cham, pp 125-147.

Lal, R. (2015). The Nexus Approach to Managing Water, Soil and Waste under Changing Climate and Growing Demands on Natural Resources. In: Kurian, M., Ardakanian, R. (eds) Governing the Nexus: Water, Soil and Waste Resources Considering Global Change. Springer International Publishing, Cham, pp 39-60.

Liu, J., Mao, G., Hoekstra, A. Y., et al. (2018). Managing the Energy-Water-Food Nexus for Sustainable Development. Appl Energy 210, 377-381. doi: 10.1016/J.APENERGY. 2017.10.064.

Liu, J., Yang, H., Cudennec, C., et al. (2017). Challenges in Operationalizing the Water-Energy-Food Nexus. Hydrol Sci J 62, 1714-1720. doi: 10.1080/02626667.2017. 1353695.

Mach, M. E., Martone, R. G., Chan, K. M. A. (2015). Human Impacts and Ecosystem Services: Insufficient Research for Trade-off Evaluation. Ecosyst Serv 16, 112-120. doi: 10.1016/J.ECOSER.2015.10.018.

Mannschatz, T., Wolf, T., Hülsmann, S. (2016). Nexus Tools Platform: Web-Based Comparison of Modelling Tools for Analysis of Water-Soil-Waste Nexus. Environ Model Softw 76, 137-153. doi: 10.1016/J.ENVSOFT.2015.10.031.

Martinez-Hernandez, E., Leach, M., Yang, A. (2017). Understanding Water-Energy-Food and Ecosystem Interactions Using the Nexus Simulation Tool NexSym. Appl Energy 206, 1009-1021. doi: 10.1016/J.APENERGY.2017.09.022.

Mochizuki, J., Magnuszewski, P., Linnerooth-Bayer, J. (2018). Games for Aiding Stakeholder Deliberation on Nexus Policy Issues. In: Hülsmann, S., Ardakanian, R. (eds) Managing Water, Soil and Waste Resources to Achieve Sustainable Development Goals: Monitoring and Implementation of Integrated Resources Management. Springer International Publishing, Cham, pp 93-124.

Nilsson, M., Chisholm, E., Griggs, D., et al. (2018). Mapping Interactions between the Sustainable Development Goals: Lessons Learned and Ways Forward. Sustain Sci 13, 1489-1503. doi: 10.1007/s11625-018-0604-z.

Raudsepp-Hearne, C., Peterson, G. D. (2016). Scale and Ecosystem Services: How Do Observation, Management, and Analysis Shift with Scale? Lessons from Quebec. Ecol Soc 21, doi: 10.5751/ES-08605-210316.

Rockström, J., Steffen, W., Noone, K., et al. (2009). Planetary Boundaries: Exploring the Safe Operating Space for Humanity. Ecol Soc 14, 32. doi: 10.5751/ES-03180-140232.

Roidt, M., Avellán, T. (2019). Learning from Integrated Management Approaches to Implement the Nexus. J Environ Manage 237, 609-616. doi: 10.1016/J.JENVMAN. 2019.02.106. 
Seppelt, R., Dormann, C. F., Eppink, F. V., et al. (2011). A Quantitative Review of Ecosystem Service Studies: Approaches, Shortcomings and the Road Ahead. J Appl Ecol 48, 630-636. doi: 10.1111/j.1365-2664.2010.01952.x.

Smajgl, A. (2018). Participatory Processes and Integrated Modelling Supporting Nexus Implementations. In: Hülsmann, S., Ardakanian, R. (eds) Managing Water, Soil and Waste Resources to Achieve Sustainable Development Goals: Monitoring and Implementation of Integrated Resources Management. Springer International Publishing, Cham, pp 71-92.

UNU-FLORES, Hettiarachchi, Hiroshan and Ardakanian, Reza. (2016). Safe Use of Wastewater in Agriculture: Good Practice Examples. United Nations University Institute for Integrated Management of Material Fluxes and of Resources (UNU-FLORES), Dresden.

Weber, M., Rinke, K., Hipsey, M. R., Boehrer, B. (2017). Optimizing Withdrawal from Drinking Water Reservoirs to Reduce Downstream Temperature Pollution and Reservoir Hypoxia. J Environ Manage 197, 96-105. doi: 10.1016/J.JENVMAN.2017. 03.020.

Wiek, A., Farioli, F., Fukushi, K., Yarime, M. (2012). Sustainability Science: Bridging the Gap between Science and Society. Sustain Sci 7:1-4. doi: 10.1007/s11625-011-0154-0.

Zabel, F., Delzeit, R., Schneider, J. M., et al. (2019). Global Impacts of Future Cropland Expansion and Intensification on Agricultural Markets and Biodiversity. Nat Commun 10, 2844. doi: 10.1038/s41467-019-10775-z.

Zhang, L., Schwärzel, K. (2017a) Multifunctional Land-Use Systems for Managing the Nexus of Environmental Resources. Springer International Publishing.

Zhang, L., Schwärzel, K. (2017b) Implementation of Multifunctional Land Management: Research Needs. In: Zhang, L., Schwärzel, K. (eds) Multifunctional Land-Use Systems for Managing the Nexus of Environmental Resources. Springer International Publishing, Cham, pp 137-148. 